\title{
Fabrication of Vertical Axis Wind Turbine
}

\author{
Dr. Ch. S. Naga Prasad \\ Professor \& Principal, Department of Mechanical Engineering, GIITS Engineering College, Aganampudi, \\ Visakhapatnam (DT), A.P, India
}

\begin{abstract}
Families living in rural areas who do not have access to the national grid may have to travel long distances and wait long times for their batteries to be recharged at commercial centers. Practical action has developed reliable and cost effective wind energy systems for charging batteries to help meet the electrical energy needs of these people. Small scale wind energy generators also have the potential to stimulate village level charging enterprises for either community or private use. Therefore practical action aims to develop and promote local industries capable of manufacturing and maintaining the generators. Modern wind energy systems consist of three basic components: a tower on which the wind turbine is mounted; a rotor that is turned by the wind; and the nacelle, which houses the equipment, including the generator, that converts the mechanical energy in the spinning rotor into electricity. The tower supporting the rotor and generator must be strong. Rotor blades need to be light and strong in order to be aerodynamically efficient and to withstand prolonged use in high winds. In this a high way wind turbine is designed and modeled using CREO parametric.
\end{abstract}

Key words: Finite element analysis, high way wind turbine, fabrication of wind turbine.

\section{INTRODUCTION}

\section{RENEWABLE SOURCES}

Renewable energy and Renewable energy commercialization

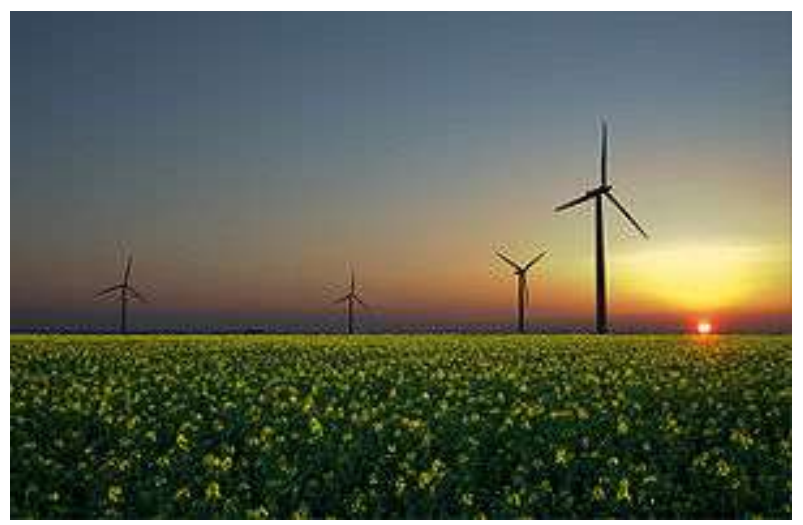

The wind, sun, and biomass are three renewable energy sources.

Renewable energy is generally defined as energy that comes from resources which are naturally replenished on a human timescale such as sunlight, wind, rain, tides, waves and geothermal heat. Renewable energy replaces conventional fuels in four distinct areas: electricity generation, hot water/space heating, motor fuels, and rural (offgrid)energy services.

About $16 \%$ of global final energy consumption presently comes from renewable resources, with $10 \%$ of all energy from traditional biomass, mainly used for heating, and 3.4\% from hydroelectricity. New renewable (small hydro, modern biomass, wind, solar, geothermal, and biofuels) account for another $3 \%$ and are growing rapidly. At the national level, at least 30 nations around the world already have renewable energy contributing more than $20 \%$ of energy supply. National renewable energy markets are projected to continue to grow strongly in the coming decade and beyond. Wind power, for example, is growing at the rate of 30\% annually, with a worldwide installed capacity of 282,482 megawatts (MW) at the end of 2012.

Renewable energy resources exist over wide geographical areas, in contrast to other energy sources, which are concentrated in a limited number of countries. Rapid deployment of renewable energy and energy efficiency is 


\section{IARJSET

resulting in significant energy security, climate change mitigation, and economic benefits. In international public opinion surveys there is strong support for promoting renewable sources such as solar power and wind power.

While many renewable energy projects are large-scale, renewable technologies are also suited to rural and remote areas and developing countries, where energy is often crucial in human development. United Nations' Secretary-General Ban $\mathrm{Ki}$-moon has said that renewable energy has the ability to lift the poorest nations to new levels of prosperity

\section{NON-CONVENTIONAL ENERGY SOURCES}

The contemporary non-conventional sources of energy like wind, tidal, solar etc. were the conventional sources until James Watt invented the steam engine in the eighteenth century. In fact, the New World was explored by man using wind-powered ships only. The non-conventional sources are available free of cost, are pollution-free and inexhaustible. Man has used these sources for many centuries in propelling ships, driving windmills for grinding corn and pumping water, etc.

Because of the poor technologies then existing, the cost of harnessing energy from these sources was quite high. Also because of uncertainty of period of availability and the difficulty of transporting this form of energy, to the place of its use are some of the factors which came in the way of its adoption or development. The use of fossil fuels and nuclear energy replaced totally the non-conventional methods because of inherent advantages of transportation and certainty of availability; however these have polluted the atmosphere to a great extent. In fact, it is feared that nuclear energy may prove to be quite hazardous in case it is not properly controlled.

In 1973 the Arab nations placed an embargo on petroleum. People began to realise that the fossil fuels are not going to last longer and that remaining reserves should be conserved for the petro-chemical industry. But unfortunately, both nuclear and coal energy pose serious environmental problems. The combustion of coal may upset the planet's heat balance. The production of carbon dioxide and sulphur dioxide may adversely affect the ability of the planet to produce food for its people. Coal is also a valuable petro-chemical and from long term point of view it is undesirable to burn coal for generation of electricity. The major difficulty with nuclear energy is waste disposal and accidental leakage (e.g. leakage at Chernobyl nuclear power plant).

As a result of these problems, it was decided by almost all the countries to develop and harness the non-conventional sources of energy, even though they are relatively costlier as compared to fossil-fuel sources. It is hoped that with advancement in technology and more research in the field of development of non-conventional sources of energy, these sources may prove to be cost-effective as well. The future of wind, solar, tidal and other energy sources is bright and these will play an important role in the world energy scenario.

\section{INTRODUCTION TO WIND POWER}

Wind power is the conversion of wind energy into a useful form of energy, such as using wind turbines to make electrical power, windmills for mechanical power, wind pumps for water pumping or drainage, or sails to propel ships. Large wind farms consist of hundreds of individual wind turbines which are connected to the electric power transmission network. For new constructions, onshore wind is an inexpensive source of electricity, competitive with or in many places cheaper than fossil fuel plants. Small onshore wind farms provide electricity to isolated locations. Utility companies increasingly buy surplus electricity produced by small domestic wind turbines. Offshore wind is steadier and stronger than on land, and offshore farms have less visual impact, but construction and maintenance costs are considerably higher.

Wind power, as an alternative to fossil fuels, is plentiful, renewable, widely distributed, clean, produces no greenhouse gas emissions during operation and uses little land. The effects on the environment are generally less problematic than those from other power sources. As of 2011, Denmark is generating more than a quarter of its electricity from wind and 83 countries around the world are using wind power to supply the electricity grid. In 2010 wind energy production was over $2.5 \%$ of total worldwide electricity usage, and growing rapidly at more than $25 \%$ per annum.

Wind power is very consistent from year to year but has significant variation over shorter time scales. As the proportion of wind power in a region increases, a need to upgrade the grid, and a lowered ability to supplant conventional production can occur. Power management techniques such as having excess capacity storage, geographically distributed turbines, dispatchable backing sources, storage such as pumped-storage hydroelectricity, exporting and importing power to neighboring areas or reducing demand when wind production is low, can greatly mitigate these problems. In addition, weather forecasting permits the electricity network to be readied for the predictable variations in production that occur. 


\section{HISTORY}

\section{Mechanical power}

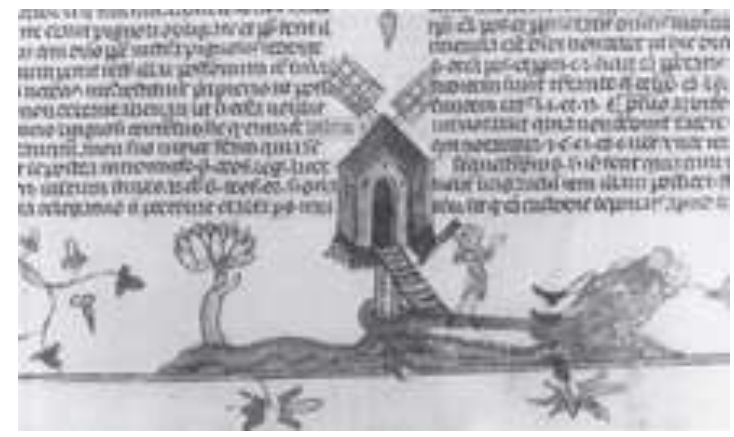

Medieval depiction of a wind mill

Sailboats and sailing ships have been using wind power for thousands of years, and architects have used wind-driven natural ventilation in buildings since similarly ancient times. The use of wind to provide mechanical power came somewhat later in antiquity. The wind wheel of the Greek engineer Heron of Alexandria in the 1st century AD is the earliest known instance of using a wind-driven wheel to power a machine.

The first windmills were in use in Persia at least by the 9th century and possibly as early as the 7th century. The use of windmills became widespread across the Middle East and Central Asia, and later spread to China and India. By 1000 $\mathrm{AD}$, windmills were used to pump seawater for salt-making in China and Sicily. Windmills were used extensively in Northwestern Europe to grind flour from the 1180s, and wind pumps were used to drain land for agriculture and for building. Early immigrants to the New World brought the technology with them from Europe.

In the US, the development of the water-pumping windmill was the major factor in allowing the farming and ranching of vast areas otherwise devoid of readily accessible water. Wind pumps contributed to the expansion of rail transport systems throughout the world, by pumping water from water wells for steam locomotives. The multi-bladed wind turbine atop a lattice tower made of wood or steel was a century a fixture of the landscape throughout rural America.

In 1881, Lord Kelvin proposed using wind power when coal ran out, as "so little of it is left". Solar power was also proposed, at about the same time.

\section{PROBLEM DESCRIPTION}

The objective of this project is to make a 3D model of the connecting rod and study the static and model behavior of the cantilever beam by performing the finite element analysis. 3D modeling software (PRO-Engineer) was used for designing and analysis software (ANSYS) was used for static and modal analysis.

\section{The methodology followed in the project is as follows:}

- Create a 3D model of the cantilever beam assembly using parametric software creo.

- Convert the surface model into Para solid file and import the model into ANSYS to do analysis.

- Perform static analysis on the cantilever beam.

- Perform model analysis on the existing model of the cantilever beam.

\section{INTRODUCTION TO CAD/CAE}

Computer-aided design (CAD), also known as computer-aided design and drafting (CADD), is the use of computer technology for the process of design and design-documentation.

\subsection{INTRODUCTION TO CREO PARAMETRIC}

Pro/ENGINEER Wildfire is the standard in 3D product design, featuring industry-leading productivity tools that promote best practices in design while ensuring compliance with your industry and company standards. Integrated Pro/ENGINEER CAD/CAM/CAE solutions allow you to design faster than ever, while maximizing innovation and quality to ultimately create exceptional products.

Different modules in creo parametric software

Part design, Assembly, Drawing\& Sheet metal. 


\subsection{INTRODUCTION TO FINITE ELEMENT METHOD:}

Finite Element Method (FEM) is also called as Finite Element Analysis (FEA). Finite Element Method is a basic analysis technique for resolving and substituting complicated problems by simpler ones, obtaining approximate solutions Finite element method being a flexible tool is used in various industries to solve several practical engineering problems. In finite element method it is feasible to generate the relative results.

\section{RESULTS AND DISCUSSIONS}

5.1. Models using creo parametric: The cantilever beam is modeled using the given specifications and design formula from data book. The outer casing body profile is sketched in sketcher and then it is extruded using extrude option.

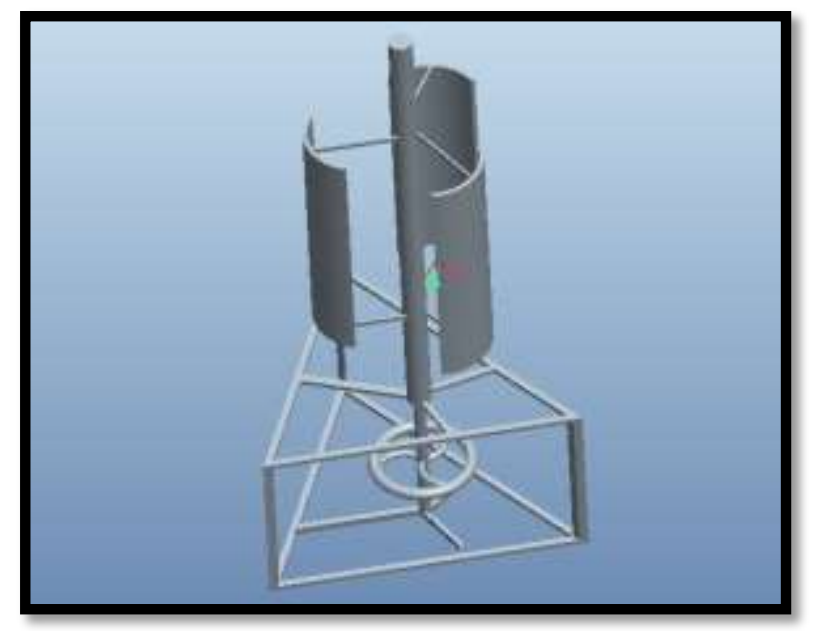

\section{CONCLUSION}

Modern wind energy systems consist of three basic components: a tower on which the wind turbine is mounted; a rotor that is turned by the wind; and the nacelle, which houses the equipment, including the generator, that converts the mechanical energy in the spinning rotor into electricity. The tower supporting the rotor and generator must be strong. Rotor blades need to be light and strong in order to be aerodynamically efficient and to withstand prolonged use in high winds. The wind turbine blades made with aluminum material. In this a high way wind turbine is designed and modeled using pro-engineer. The highway wind turbine is fabricated.

\section{REFERENCES}

[1] Z.W. Yu, X.L. Xu "Failure analysis of diesel engine rocker arms" Engineering Failure Analysis, Volume 13, Issue 4, June 2006, Pages 598-605.

[2] Chin-Sung Chung, Ho-Kyung Kim "Safety evaluation of the rocker arm of a diesel engine" Materials \& Design, Volume 31, Issue 2,February 2010, Pages 940-945

[3] Dong-Woo Lee, Soo-Jin Lee, Seok-Swoo Cho, WonSikJoo "Failure of rocker arm shaft for 4-cylinder SOHC engine".

[4] Dong Woo Lee, SeokSwoo Cho and Won SikJoo "An estimation of failure stress condition in rocker arm shaft through FEA and microscopic fractography"

[5] James M. miller "Rocker arm having perpendicular geometry at valve mid lift" united states patent Appl. No.211, 638.Dec1, 1980

\section{BIOGRAPHY}

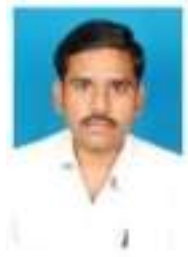

DR. Ch. S. Naga Prasad received his M.Tech Degree on Heat power Refrigerator and AC from JNTU, Anantapur in 2002 and Ph.D on IC Engines (Thermal Engg) from JNTU, Hyderabad in 2011. He is currently working as Professor \& Principal in Gonna Institute of Information Technology and sciences, Aganampudi, Visakhapatnam, A.P, INDIA. 